\title{
Evaluation of Antimicrobial Activity of Essential Oil of Eshvark (Rhazya stricta) Against Two Strains of Staphylococcus aureus and Listeria monocytogenes
}

\author{
Mehrdad Asadian, ${ }^{1}$ Hemadollah Zarei, ${ }^{1,}{ }^{*}$ Barat Ali Fakheri, ${ }^{1}$ and Leyla Fahmideh ${ }^{1}$ \\ ${ }^{1}$ Department of Plant Breeding and Biotechnology, Faculty of Agriculture, University of Zabol, Zabol, IR Iran \\ "Corresponding author: Hemadollah Zarei, Department of Plant Breeding and Biotechnology, Faculty of Agriculture, University of Zabol, Zabol, IR Iran. E-mail: \\ h.zarei@gmail.com
}

Received 2015 September 30; Revised 2017 January 16; Accepted 2017 January 29.

\begin{abstract}
Background: Many diseases are often caused by bacteria, including those caused by Staphylococcus aureus and Listeria monocytogenes. Staphylococcus aureus has a hospital infection source and can cause simple skin diseases such as rashes, as well as more severe diseases, such as pneumonia and meningitis. Listeria monocytogenes has an environmental source, such as water, soil and food, and attacks the central nervous system and causes neurological symptoms, even leading to death.

Objectives: This study aimed at evaluating antimicrobial effects of ethanol extract and essential oil Eshvark against clinical isolates of S. aureus and L. monocytogenes, which are resistant to antibiotics.

Methods: Different strains of S. aureus bacteria were isolated from Bu-Ali hospital of Zahedan, and standard strains of $L$. monocytogenes (PTCC 1630) were provided as a lyophilized vial in Iranian collection center of fungus and bacteria (Iranian research organization for Science and industry). In this study, the essential oil of Razya stritca was obtained by Clevenger. Then the minimum inhibitory concentrations were investigated to characterize the antibacterial activities of this essential oil.

Results: These tests showed that the approximate minimum inhibitory concentration was at concentrations of 5 and $10 \mathrm{mg}$ per milliliter, and the amount of inhibitory concentration for S. aureus was 25/83 and 6/17 while this amount for L. monocytogenes was $5 / 53$ and $1 / 7$, and the minimum bactericidal concentration (MBC) was also at concentrations of 5 and $10 \mathrm{mg}$ per milliliter.

Conclusions: This study confirmed the antimicrobial potential of investigated plants and their usefulness in treatment of resistant isolates of S. aureus and L. monocytogenes.
\end{abstract}

Keywords: Eshvark, Oil, Anti- Bacteria, MIC, MBC

\section{Background}

Staphylococcus aureus are gram-positive aerobic bacteria, and thusthe most important species of genus Staphylococcus. They are dangerous pathogenic bacteria (1). They could produce a golden carotenoid pigment, called staphyloxanthin (it produces yellow colonies). This pigment plays a role in the pathogenesis, because it acts as an antioxidant and protects the bacteria against oxygen free radicals (2). Oxygen free radicals are produced by the host immune system for killing the bacteria (3). Staphylococcus aureus causes a wide range of infections, from simple skin infections to very serious diseases (such as pneumonia, meningitis, and endocarditic). It is known as a common cause of hospital infections, particularly wound infections after surgery (4). Every year, 500 thousand people in hospitals of United States of America are infected with Staphylococcus aureus. It is resistant to Methicillin antibiotic (MRSA) (5). Staphylococcus aureus was first isolated from a pus sample by a Scottish surgeon, Alexander
Ogston, in Scotland in 1880 (6). Listeria monocytogenes food are non-sporulation, non-branched, regular, short, anaerobic gram-positive bacteria that are isolated from soil, animal food, water, manure, meat, milk and dairy products, and vegetables (7). These bacteria cause listeriosis disease, which are common diseases between human and animals that cause primary meningitis in adults. Older patients or those with low cellular immunity are particularly susceptible to these bacteria, such as organ transplant recipients or AIDS patients (8). Listeria monocytogenes effect the central nervous system, and causes serious diseases, usually with a high mortality rate. In such a way that in case of food contamination with this bacteria, the mortality rate reaches $40 \%$ to $30 \%$ and it has been reported that in susceptible individuals, it reaches up to $75 \%$. Among those who have recovered from this disease, the neurological symptoms remain for a long time in the patients (9). Pregnancy increases the risk of listeriosis. Listeria monocytogenes in pregnant females usually causes a bacterial disease like flu, and if it is left untreated, it could lead to inflamma-

Copyright @ 2017 , International Journal of Infection. This is an open-access article distributed under the terms of the Creative Commons Attribution-NonCommercial 4.0 International License (http://creativecommons.org/licenses/by-nc/4.0/) which permits copy and redistribute the material just in noncommercial usages, provided the original work is properly cited. 
tion of placenta or amniotic membrane, and fetus's infection and finally abortion or premature birth (10). The most important way of transfer is through foods. Since these bacteria could be found everywhere, to prevent infections, further control and monitoring of food production and distribution cycle is necessary. The potential risk of contamination with these bacteria has been demonstrated in meat products, raw and pasteurized milk in many studies from different countries (11). The situation of L. monocytogenes is unknown in Iran and little information is available about the presence of L. monocytogenes in food products that are consumed in Iran. Iranians' eating habits are also different from those in the West, so there is lower risk of infection with this bacteria in Iran (12). Essential oils are volatile compounds that are obtained through various methods, such as distillation, extraction or distillation in a vacuum by solvent extraction plants. Essential oils are aromatic substances that have a strong odor and smell, and chemically contain aromatic ring and benzene and their main ingredients are phenol and oxygen (13). Natural essential oils and their components are the most effective agents of microbial compounds that due to their high purity during preparation, play an important role in controlling microorganisms. In terms of chemical structure, essential oils are a mixture of esters, aldehydes, alcohols, acetone and terpenoids, the components of which are different depending on the plants (14). In addition, these materials are found in different parts of the plant, such as bark, roots, leaves, stems, fruit, seeds, and flowers. Essential oils prevent the production of DNA, RNA, proteins, and polysaccharides in fungal and bacterial cells (15). Secondary metabolites of medicinal plants, such as essential oils and plant extracts, have been studied for their anti-microbial effects. It has become clear that most essential oils that are extracted from herbal plants have antifungal, anti-parasitic, antibacterial and anti-virus properties. Thus, identifying plants that have antibacterial properties, and separation and purification of their compounds are effective in the treatment of infectious diseases, and could be a useful way to treat infections resistant to antibiotics. Also, the role of essential oils in a number of medicinal plants to prevent the uncontrolled growth of cancer cells has been demonstrated (16).

Eshvark is a plant with the scientific name of Rhazya stricta, a shrub with a height of 50 to $100 \mathrm{~cm}$ from the Apocynaceae species that grows in hot and dry areas. Eshvark is a small shrub with a central soft stem and no fluff. This plant is an indigenous shrub of Sistan and Baluchistan and Hormozgan provinces of Iran (17). It also grows in other countries, such as Afghanistan, Pakistan, Saudi Arabia, and India (18). It's Fresh and green fruits could be used for treatment of sunburn and sunstroke in the eye. Its corolla is used to quench thirst in the desert. The plant extracts could be used in the treatment of diseases, such as diabetes, fever as well as wounds treatment and to improve liver inflammation (19). Antioxidant properties of this plant has been studied in mice. Studies have shown that its leaves and extracts change enzyme activity in Transaminase Aspartate (AST) and Alanine Transaminase (ALT), and in mice cells, they cause antioxidant activity (20).

\section{Objectives}

The aim of this study was to initially evaluate the antimicrobial effects of ethanol extract and essential oil of Eshvark against clinical isolates of S. aureus and L. monocytogenes bacteria that are resistant to antibiotics. Finally, inhibitory and deadly concentrations on different strains for the purpose of introduction to the pharmaceutical industry, was determined.

\section{Methods}

\subsection{Plant Material}

The leaves of Rhazya stricta were collected from Iranshahr, southeastern Iran, and dried at room temperature. Samples were crashed and transferred to glass containers and preserved until the extraction procedure was performed in the laboratory.

\subsection{Distillation of Essential Oils}

Plant materials were subjected to steam distillation for 3 hours using a Clevenger-type apparatus. Essential oils were collected after decantation. The distilled essential oil was dried over anhydrous sodium sulfate and was filtered and stored at $4^{\circ} \mathrm{C}$.

\subsection{Isolation of Bacteria and Culture Method}

Different strains of S. aureus bacteria used in this study were isolated from Bu-Ali hospital in Zahedan; they were cultured and purified on special culture medium Mannitol Salt agar and blood agar (MERCK-Germany). These bacteria were then fully identified by using biochemical tests, such as catalase, coagulase, and DNase, then by growth on differential medium. Standard strains of L. monocytogenes (PTCC 1630) were provided as a lyophilized vial at an Iranian collection center of fungus and bacteria (Iranian research organization for Science and industrial). 


\subsection{Antimicrobial Testing of Essential Oil}

Susceptibility of bacterial isolates with multiple resistances to the plant essential oils of $R$. stricta was investigated using the dilution plate. One hundred milliliters of nutrient broth Mueller Hinton broth (MHB) was added to seven micro-titter plates. The first well received $100 \mathrm{~mL}$ of the diluted solution of the extract, after mixing, and 100 $\mathrm{mL}$ of the first plate was removed and added to the second plate, and this was carried on for the entire plate. From the last plate, $100 \mathrm{~mL}$ of culture medium containing $10^{7}$ units per $\mathrm{mL}$ was removed, and $100 \mathrm{~mL}$ of bacterial suspension equivalent to $0.5 \mathrm{McF}$ arland was added to all wells and incubated at $37^{\circ} \mathrm{C}$ for 24 hours. The first well that prevented the growth of bacteria was considered as MIC and to ensure this finding, $10 \mathrm{~mL}$ of the clear plate was transferred to the Mueller Hinton agar medium. After 24 hours, the first dilution that could kill $99.9 \%$ of bacteria showed the Minimum lethal concentration

\subsection{Sensitivity Testing of Microbes Against Antibiotics}

Sensitivity of 15 strains isolated from 2 species of S. aureus and L. monocytogenes bacteria to ampicillin, tetracycline, erythromycin, penicillin, and cefoxitine antibiotics that were obtained from Padtan Teb-e-Iran pharmaceutical company, were assessed. They were evaluated using the standard Kirby-Bauer disk diffusion method. To do so, all strains of bacteria with concentration of 5.0 McFarland (cfu/mL $108^{\mathrm{x}} 1$ ) on Mueller Hinton broth were prepared and then cultured on Mueller Hinton agar. The target disks, according to the manufacturer's instructions, were stained with every antibiotic and then were dried in sterile conditions Finally, they were placed on the surface of Mueller Hinton solid medium containing bacteria. Then, each plate was placed at $37^{\circ} \mathrm{C}$ for 24 hours, assessing and determining their resistance or sensitivity to antibiotics. Each experiment was repeated 3 times, and the results were analyzed using SPSS version 19 (USA) statistical analysis. The results of this analysis were compared with those of the national committee for clinical laboratory standards (NCCLS).

The inhibitory growth zones that are made by the action of antibiotics on petri dish, are observed as a corona (halo). They could be measured by a ruler. If the size of the inhibition zone around each whole (pit) is more than one centimeter, it is recorded as an acceptable antibiotic activity.

\subsection{Minimum Inhibitory Concentration (MIC) and Minimum Bactericidal Concentration (MBC)}

The broth micro dilution method was used to determine MIC and MBC (21). All tests were performed by
Mueller Hinton broth, supplemented with Tween 80 at a final concentration of $0.5 \%(\mathrm{v} / \mathrm{v})$. Briefly, serial doubling dilutions of the extract were prepared in a 96-well micro titer plate ranging from $0.3 \mathrm{mg} / \mathrm{mL}$ to $10.00 \mathrm{mg} / \mathrm{mL}$. To each well, $10 \mu \mathrm{L}$ of indicator solution (prepared by dissolving a 10-mg extract in $2 \mathrm{~mL}$ of DMSO) and $10 \mu \mathrm{L}$ of Mueller Hinton Broth were added. Finally, $10 \mu \mathrm{L}$ of bacterial suspension (106 CFU/mL) was added to each well to achieve a concentration of $104 \mathrm{CFU} / \mathrm{mL}$. The plates were wrapped loosely with cling film to ensure that the bacteria did not become dehydrated. The plates were prepared in triplicates, and were then placed in an incubator at $37^{\circ} \mathrm{C}$ for 18 to 24 hours. The color change was then assessed visually. The lowest concentration at which the color change occurred was taken as the MIC value. The average of 3 values was calculated providing the MIC and MBC values for the tested extract. The MIC was defined as the lowest concentration of the extract at which the microorganism does not demonstrate visible growth. The microorganism growth was indicated by turbidity. The MBC was defined as the lowest concentration of the extract at which the incubated microorganism was completely killed.

\section{Results}

\subsection{The Reaction of Two Species of Bacteria to the Antibiotics}

Antibacterial activities of several antibiotics were evaluated against 2 strains of $S$. aureus and L. monocytogenes under laboratory conditions. The results showed that these 2 bacterial strains almost showed identical behavior, yet demonstrated some differences as well. For example, 8 strains of $S$. aureus bacteria showed resistance to 3 antibiotics, and the fifth strain showed the highest resistance to all antibiotics (Table 3). The sensitivity or resistance of strains of L. monocytogenes showed that 4 strains were resistant to 3 antibiotics, but most strains were resistant to 2 antibiotics. Strain number 4, demonstrated the highest level of resistance to 4 antibiotics (Table 4). Among the antibiotics, ampicillin had the lowest inhibitory concentration for the growth of S. Aureus, which is indicative that 95\% of strains were resistant to this antibiotic, and strain number 1 demonstrated intermediate level of resistance (Table 3 ). The two antibiotics, ampicillin and cefoxitin showed the lowest inhibitory effect for the growth of L. monocytogenes (Table 4).

\subsection{The Evaluation Results of the MIC and MBC}

The results of MIC and MBC extracts on two bacterial strains used in this study are shown in Tables 5 and 6.

The results of these tests showed that the highest sensitivity concentrations were 5 and $10 \mathrm{mg} / \mathrm{L}$ in S. aureus, 2.5 
Table 1. Inhibition Zone Diameter for Each Strain of S. aureus Against Different Antibiotics

\begin{tabular}{|c|c|c|c|c|c|}
\hline \multicolumn{5}{|c|}{ Inhibition Zone Diameter for Each Strain Against Different Antibiotics, cm } & \multirow{2}{*}{$\begin{array}{c}\text { Bacterial Strain } \\
\text { S.aureus }\end{array}$} \\
\hline AMP & TET & ERT & PEN & CEF & \\
\hline 1.1 & 1 & 1.5 & 1.2 & 1.7 & 1 \\
\hline 1.9 & 1.2 & 1.7 & 1.7 & 1.1 & 2 \\
\hline 1.9 & 1.1 & 1.1 & 2 & 1.2 & 3 \\
\hline 1.9 & 1.3 & 1.5 & 1.3 & 2 & 4 \\
\hline 2 & 1.7 & 1.9 & 2 & 1.9 & 5 \\
\hline 1.8 & 1 & 2 & 2 & 1 & 6 \\
\hline 1.8 & 1.2 & 1 & 2 & 2 & 7 \\
\hline 1.7 & 1.7 & 1.1 & 1.9 & 2 & 8 \\
\hline 1.8 & 1.7 & 1 & 1.9 & 1 & 9 \\
\hline 2 & 1.7 & 1.5 & 1.1 & 1.5 & 10 \\
\hline
\end{tabular}

Table 2. Inhibition Zone Diameter for Each Strain of L. monocytogenes Against Different Antibiotics

\begin{tabular}{|c|c|c|c|c|c|}
\hline \multicolumn{5}{|c|}{ Inhibition Zone Diameter for Each Strain Against Different Antibiotics, cm } & \multirow{2}{*}{$\begin{array}{l}\text { Bacterial Strain } \\
\text { L. monocytogenes }\end{array}$} \\
\hline AMP & TET & ERT & PEN & CEF & \\
\hline 1.2 & 2 & 1.3 & 1 & 1.5 & 1 \\
\hline 1.5 & 2 & 1 & 1.2 & 1 & 2 \\
\hline 1.6 & 2 & 1.2 & 1.1 & 1.9 & 3 \\
\hline 1 & 2 & 1.7 & 1.7 & 1.5 & 4 \\
\hline 1.7 & 2 & 1.2 & 1 & 1.6 & 5 \\
\hline 1.6 & 1.3 & 1 & 1.8 & 1.7 & 6 \\
\hline 1.1 & 1.2 & 1.1 & 2 & 1.7 & 7 \\
\hline 1.7 & 1.4 & 1 & 1.9 & 1.1 & 8 \\
\hline 1.7 & 1.2 & 1.7 & 1.3 & 1 & 9 \\
\hline 1 & 1.2 & 1.3 & $\mathrm{R}$ & 1.5 & 10 \\
\hline
\end{tabular}

and $5 \mathrm{mg} / \mathrm{L}$ in L. monocytogenes (Tables 3 and 4). The turbidity of the culture medium containing bacteria that was affected by Eshvark extract was also significantly reduced. The rate of change in turbidity was caused by decrease in the growth of bacteria in culture. The results of these tests show that the Eshvark extract has greater inhibitory effect on S. aureus than L. monocytogenes.

\section{Discussion}

Today, with wide spread bacterial resistance, the world is confronted with various antibiotics (22). Therefore, obtaining more knowledge about plant extracts and compounds and their application is important to deal with pathogenic bacteria. This study also showed that S. aureus is resistant to the antibiotic ampicillin. It was also found that L. monocytogenes is resistant to cefoxitin antibiotics. One way of solving this problem is the study of substances that are found in plants (23). In the recent study the antibacterial effect of Eshvark extract on some bacteria like $\mathrm{E}$. coli has been investigated, and the results were indicative of positive effect of this plant on these bacteria (17). Due to the favorable impacts of this plant, in the current study the effect of ethanol extract of the plant on two bacteria of $S$. aureus and L. monocytogenes and its role in the treatment of diseases caused by these bacteria were studied. Regarding the reaction of bacterial strains to antibiotics, tests showed that all strains reacted similarly to a special antibiotic; this is indicative of low genetic diversity of strains in populations under study. However, the strains responded differently to various types of antibiotics and this is due to the type and mode of action of antibiotics on specific loca- 
Table 3. Sensitivity Pattern of S. aureus Strains to Antibiotics

\begin{tabular}{lccccc}
\hline \multirow{2}{*}{ aureus } & \multicolumn{5}{c}{ Antibiotics } \\
\cline { 2 - 6 } & AMP & TET & ERT & PEN & CEF \\
\hline $\mathbf{1}$ & $\mathrm{I}$ & $\mathrm{S}$ & $\mathrm{R}$ & $\mathrm{I}$ & $\mathrm{R}$ \\
$\mathbf{2}$ & $\mathrm{R}$ & $\mathrm{I}$ & $\mathrm{R}$ & $\mathrm{R}$ & $\mathrm{S}$ \\
$\mathbf{3}$ & $\mathrm{R}$ & $\mathrm{I}$ & $\mathrm{I}$ & $\mathrm{R}$ & $\mathrm{I}$ \\
$\mathbf{4}$ & $\mathrm{R}$ & $\mathrm{I}$ & $\mathrm{R}$ & $\mathrm{I}$ & $\mathrm{R}$ \\
\hline $\mathbf{5}$ & $\mathrm{R}$ & $\mathrm{R}$ & $\mathrm{R}$ & $\mathrm{R}$ & $\mathrm{R}$ \\
$\mathbf{6}$ & $\mathrm{R}$ & $\mathrm{S}$ & $\mathrm{R}$ & $\mathrm{R}$ & $\mathrm{S}$ \\
\hline $\mathbf{7}$ & $\mathrm{R}$ & $\mathrm{I}$ & $\mathrm{S}$ & $\mathrm{R}$ & $\mathrm{R}$ \\
$\mathbf{8}$ & $\mathrm{R}$ & $\mathrm{R}$ & $\mathrm{S}$ & $\mathrm{R}$ & $\mathrm{R}$ \\
\hline $\mathbf{9}$ & $\mathrm{R}$ & $\mathrm{R}$ & $\mathrm{S}$ & $\mathrm{R}$ & $\mathrm{S}$ \\
\hline $\mathbf{1 0}$ & $\mathrm{R}$ & $\mathrm{R}$ & $\mathrm{R}$ & $\mathrm{S}$ & $\mathrm{R}$ \\
\hline & & & & & \\
\hline
\end{tabular}

Table 4. Sensitivity Pattern of $L$. monocytogenes Strains to Antibiotics

\begin{tabular}{lccccc}
\hline \multirow{2}{*}{ L. monocytogenes } & \multicolumn{5}{c}{ Antibiotics } \\
\cline { 2 - 6 } & AMP & TET & ERT & PEN & CEF \\
\hline $\mathbf{1}$ & I & R & I & S & R \\
$\mathbf{2}$ & R & R & S & I & S \\
\hline $\mathbf{3}$ & R & R & I & S & R \\
\hline $\mathbf{4}$ & S & R & R & R & R \\
\hline $\mathbf{5}$ & R & R & I & S & R \\
\hline $\mathbf{6}$ & R & I & S & R & R \\
\hline 7 & S & S & I & R & R \\
\hline $\mathbf{8}$ & R & I & S & R & S \\
\hline $\mathbf{9}$ & R & S & R & I & S \\
\hline $\mathbf{1 0}$ & S & S & I & R & R \\
\hline
\end{tabular}

Table 5. The Percentage of S. aureus Strains Sensitive to Dilution of the Eshvark Extract

\begin{tabular}{lccccccc}
\hline Extracts Concentration & $\mathbf{0 . 5}$ & $\mathbf{1}$ & $\mathbf{1 . 5}$ & $\mathbf{2}$ & $\mathbf{2 . 5}$ & $\mathbf{5}$ & $\mathbf{1 0}$ \\
\hline MIC & 0 & 0 & 0 & 5.5 & 7.1 & 83.25 & 17.6 \\
MBC & 0 & 0 & 0 & 0 & 5.5 & 7.1 & 94.11 \\
\hline
\end{tabular}

Table 6. The Percentage of L. monocytogenes Strains Sensitive to Dilution of the Eshvark Extract

\begin{tabular}{lccccccc}
\hline Extracts Concentration & $\mathbf{0 . 5}$ & $\mathbf{1}$ & $\mathbf{1 . 5}$ & $\mathbf{2}$ & $\mathbf{2 . 5}$ & $\mathbf{5}$ & $\mathbf{1 0}$ \\
\hline MIC & 0 & 0 & 0 & 5.3 & 8.5 & 53.5 & 7.1 \\
MBC & 0 & 0 & 0 & 0 & 5.3 & 8.5 & 77.7 \\
\hline
\end{tabular}
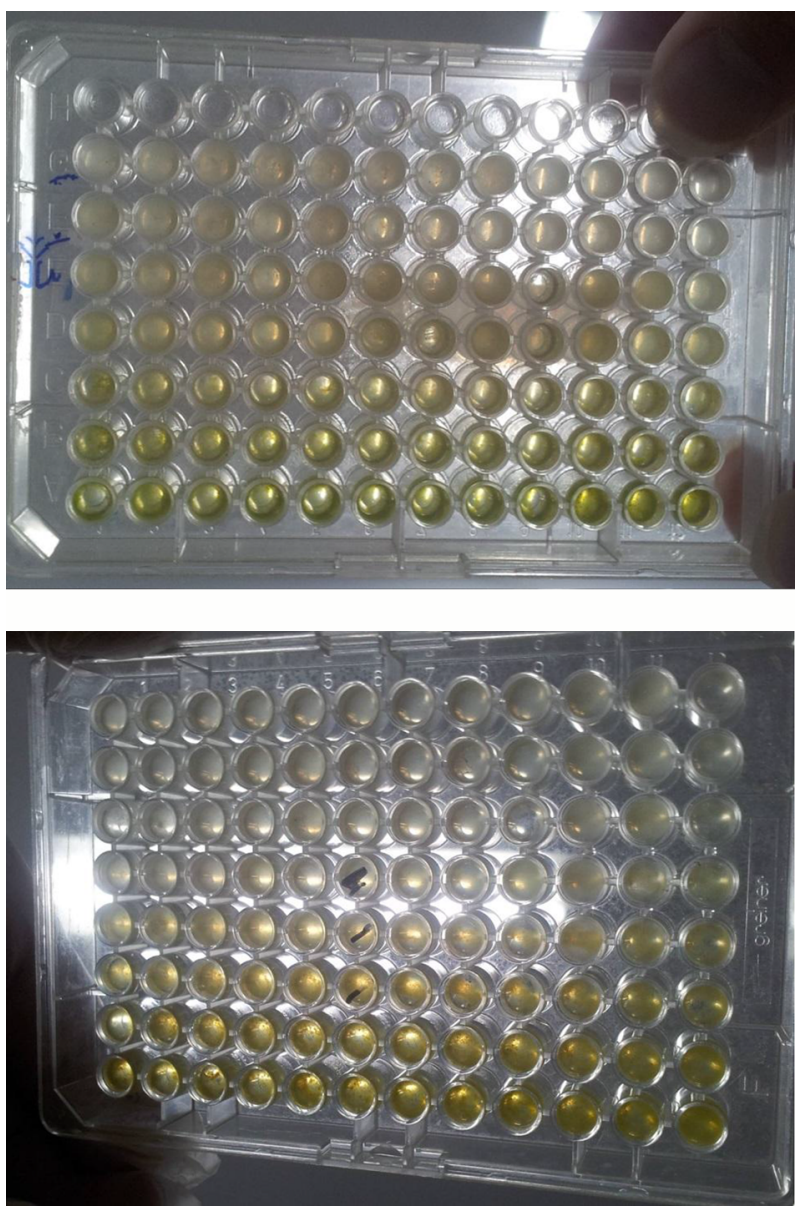

Figure 1. 96-Well Plate Used in the Micro Dilution Technique: Reducing the Amount of Turbidity in Each Plate Containing Medium Culture

tions within the cell, such as mitochondria, plasma membrane, and the nucleus. The results of this study showed that the inhibitory effect of Eshvark extract on S. aureus was greater than that of L. monocytogenes. This could be due to a stronger cell wall in L. monocytogenes (24). The existence of free radicals in the extract of this plant could also be effective in inhibiting bacteria and the ethyl acetate compound in the extract could create maximum inhibitory effect (25). In a study conducted in China, the effect of 19 drug species, against hospital strains of $S$. aureus showed that the concentration of this herbal extract with a minimal inhibitory effect was at $10 \mathrm{mg}$ per $\mathrm{mL}$ (21). These tests correspond with the findings of the current research. In another study, the antimicrobial effect of essential oils of several plant species on L. monocytogenes was investigated. The results showed that the essential oil of cloves and Hindi mint had good effects against the bacteria $(26,27)$. However, studies showed that the effect of the essential oils on 
E. coli was greater, because $E$. coli bacteria is gram negative and L. monocytogenes is gram positive. Therefore, it demonstrated greater sensitivity to these essences. This is probably due to the differences in the strength of the cell wall of gram-negative and gram-positive bacteria and lack of membrane in gram-positive bacteria (24). It is important to know that the compositions in plant extracts may introduce the most effective agent in the extract. Taking into consideration the diversity of these compositions, analysis of these compounds by means of various chromatographies could identify effective compounds and introduce them to the pharmaceutical industry.

After general introduction of a plant to deal with the disease caused by bacteria, further studies are required to determine the active ingredients of that plant. It should also be noted that due to strains resistant to common antibiotics, it is necessary to use a lower dose for each patient, and so, the extract of boiled Eshvark must be administered to the patient for favorable impact on controlling the disease.

\section{References}

1. Boost MV, O'Donoghue MM, James A. Prevalence of Staphylococcus aureus carriage among dogs and their owners. Epidemiol Infect. 2008;136(7):953-64. doi: 10.1017/S0950268807009326. [PubMed: $17678561]$.

2. Liu GY, Essex A, Buchanan JT, Datta V, Hoffman HM, Bastian JF, et al. Staphylococcus aureus golden pigment impairs neutrophil killing and promotes virulence through its antioxidant activity. $J$ Exp Med. 2005;202(2):209-15. doi: 10.1084/jem.20050846. [PubMed: 16009720].

3. Francois P, Schrenzel J. In: Staphylococcus: Molecular Genetics. Lindsay JA, editor. ; 2008. pp. 71-90.Rapid diagnosis and typing of Staphylococcus aureus.

4. Waters AE, Contente-Cuomo T, Buchhagen J, Liu CM, Watson L, Pearce $\mathrm{K}$, et al. Multidrug-Resistant Staphylococcus aureus in US Meat and Poultry. Clin Infect Dis. 2011;52(10):1227-30. doi: 10.1093/cid/cir181. [PubMed: 21498385].

5. Cimolai N. MRSA and the environment: implications for comprehensive control measures. EurJ Clin Microbiol Infect Dis. 2008;27(7):481-93. doi: 10.1007/s10096-008-0471-0. [PubMed: 18273652].

6. Schneewind O, Fowler A, Faull KF. Structure of the cell wall anchor of surface proteins in Staphylococcus aureus. Science. 1995;268(5207):103-6. doi:10.1126/science.7701329. [PubMed: 7701329].

7. Momtaz H, Yadollahi S. Molecular characterization of Listeria monocytogenes isolated from fresh seafood samples in Iran. Diagn Pathol. 2013;8:149. doi: 10.1186/1746-1596-8-149. [PubMed: 24033984].

8. Ramaswamy V, Cresence VM, Rejitha JS, Lekshmi MU, Dharsana KS, Prasad SP, et al. Listeria-review of epidemiology and pathogenesis. $J$ Microbiol Immunol Infect. 2007;40(1):4-13. [PubMed: 17332901].

9. Schmid MW, Ng EY, Lampidis R, Emmerth M, Walcher M, Kreft J, et al. Evolutionary history of the genus Listeria and its virulence genes. Syst Appl Microbiol. 2005;28(1):1-18. doi: 10.1016/j.syapm.2004.09.005. [PubMed: 15709360].

10. Smith B, Kemp M, Ethelberg S, Schiellerup P, Bruun BG, GernerSmidt P, et al. Listeria monocytogenes: maternal-foetal infections in Denmark 1994-2005. Scand J Infect Dis. 2009;41(1):21-5. doi: 10.1080/00365540802468094. [PubMed: 18855227].

11. Seifi S. Prevalence and risk factors for Listeria monocytogenes contamination in Iranian broiler flocks. Acta Sci Vet. 2012;40(4):1074.

12. Jamshidi A, Khanzadi S. The presence of Listeria monocytogenes in raw milk samples in Mashhad, Iran. Iran JVet Res. 2011;11.

13. Adwan G, Mhanna M. Synergistic effects of plant extracts and antibiotics on Staphylococcus aureus strains isolated from clinical specimens. Middle-East J Sci Res. 2008;3(3):134-9.

14. Aqil F, Khan MS, Owais M, Ahmad I. Effect of certain bioactive plant extracts on clinical isolates of beta-lactamase producing methicillin resistant Staphylococcus aureus. J Basic Microbiol. 2005;45(2):106-14. doi: 10.1002/jobm.200410355. [PubMed:15812867].

15. Kalemba D, Kunicka A. Antibacterial and antifungal properties of essential oils. Curr Med Chem. 2003;10(10):813-29. doi 10.2174/0929867033457719. [PubMed: 12678685].

16. Sibanda T, Okoh A. The challenges of overcoming antibiotic resistance: Plant extracts as potential sources of antimicrobial and resistance modifying agents. Afr J Biotechnol. 2007;6(25).

17. Akhgari A. Alkaloids of in vitro cultures of Rhazya stricta. University of Helsinki, Finland; 2015.

18. Park S, Ruhlman TA, Sabir JS, Mutwakil MH, Baeshen MN, Sabir MJ, et al. Complete sequences of organelle genomes from the medicinal plant Rhazya stricta (Apocynaceae) and contrasting patterns of mitochondrial genome evolution across asterids. BMC Genomics. 2014;15:405. doi: 10.1186/1471-2164-15-405. [PubMed: 24884625].

19. Yates SA, Chernukhin I, Alvarez-Fernandez R, Bechtold U, Baeshen M, Baeshen N, et al. The temporal foliar transcriptome of the perennial C3 desert plant Rhazya stricta in its natural environment. BMC Plant Biol. 2014;14:2. doi: 10.1186/1471-2229-14-2. [PubMed: 24387666].

20. Ali BH, Bashir AK, Rasheed RA. Effect of the traditional medicinal plants Rhazya stricta, Balanitis aegyptiaca and Haplophylum tuberculatum on paracetamol-induced hepatotoxicity in mice. Phytother Res. 2001;15(7):598-603. doi:10.1002/ptr.818. [PubMed: 11746841].

21. Zuo GY, Wang GC, Zhao YB, Xu GL, Hao XY, Han J, et al. Screening of Chinese medicinal plants for inhibition against clinical isolates of methicillin-resistant Staphylococcus aureus (MRSA). J Ethnophar macol. 2008;120(2):287-90. doi: 10.1016/j.jep.2008.08.021. [PubMed: 18804522].

22. Udikovic-Kolic N, Wichmann F, Broderick NA, Handelsman J. Bloom of resident antibiotic-resistant bacteria in soil following manure fertilization. Proc Natl Acad Sci U S A. 2014;111(42):15202-7. doi: 10.1073/pnas.1409836111. [PubMed: 25288759].

23. Friedman M. Antibiotic-resistant bacteria: prevalence in food and inactivation by food-compatible compounds and plant extracts. $J$ Agric Food Chem. 2015;63(15):3805-22. doi: 10.1021/acs.jafc.5b00778. [PubMed: 25856120].

24. Akbari J, Saeedi M, Farzin D, Morteza-Semnani K, Esmaili Z. Transdermal absorption enhancing effect of the essential oil of Rosmarinus officinalis on percutaneous absorption of Na diclofenac from topical gel.Pharm Biol. 2015;53(10):1442-7. doi:10.3109/13880209.2014.984855. [PubMed: 25853969].

25. Ardalan T, Ardalan P, Heravi MM. Kinetic study of free radicals scavenging by saffron petal extracts. J Chem Health Risk. 2012;2(4):29-36.

26. Ullah N, Khurram M, Amin MU, Afridi HH, Khan FA, Khayam SMU. Comparison of Phytochemical constituents and antimicrobial activities of Mentha spicata from four northern districts of Khyber pakhtunkhwa. J Appl Pharm Sci. 2011;1(7):72-6.

27. Bayoub K, Baibai T, Mountassif D, Retmane A, Soukri A. Antibacterial activities of the crude ethanol extracts of medicinal plants against Listeria monocytogenes and some other pathogenic strains. Afr JBiotechnol. 2010;9(27):4251-8. 